\title{
New insights into Pablo Picasso's La Miséreuse accroupie (Barcelona, 1902) using X-ray fluorescence imaging and reflectance spectroscopies combined with micro-analyses of samples
}

\author{
Emeline Pouyet ${ }^{1}$ (I) Kenneth Brummel ${ }^{2} \cdot$ Sandra Webster-Cook ${ }^{2} \cdot$ John Delaney $^{3} \cdot$ Catherine Dejoie $^{4}$. \\ Gianluca Pastorelli ${ }^{1} \cdot$ Marc Walton $^{1}$
}

Received: 27 February 2019 / Accepted: 23 June 2020 / Published online: 22 July 2020

(c) Springer Nature Switzerland AG 2020

\begin{abstract}
The existence of underlying structures in an x-radiograph of La Miséreuse accroupie (1902), a Blue Period painting in the collection of the Art Gallery of Ontario (AGO), prompted a comprehensive technical study to unpack how Picasso actually made this iconic work of art. A methodology was used in which 2D macroscopic data were collected in situ using fiber optics reflectance spectroscopy and macro-X-ray fluorescence mapping. It confirmed that Picasso painted over an earlier composition. It also revealed, between the former composition and the finished work, an earlier version of the crouching woman painted by Picasso. The preliminary pigments distribution obtained from both hidden and visible compositions guided the sampling of micro-fragments to perform supplementary micro-analyses. Analyses at the microscale allowed the identification of the different pigments present in the complex stratigraphy of the painting. Scanning Electron Microscopy, Fourier Transform spectroscopies and 2D micro X-Ray Powder diffraction provided further insights into Picasso's early palette.
\end{abstract}

Keywords Picasso · Pigment identification · Hidden composition · Macro X-ray fluorescence · Fiber optics reflectance spectroscopy $\cdot$ Micro spectroscopic analyses

\section{Background}

La Miséreuse accroupie (1902, oil on canvas, $101.2 \times 66 \mathrm{~cm}$, Art Gallery of Ontario, Toronto, Canada, Z. I, 121) (Fig. 1a) is believed to have been painted in Barcelona after Picasso's return from Paris in January 1902. The painting was bequeathed to what was then called the Art Gallery of Toronto by an anonymous donor who escaped to Canada from Nazi Germany in 1936. Upon returning to Germany in 1963 , she gave the painting to the gallery as an expression of gratitude for having provided a place of solace during her time in Toronto. Depicted in La Miséreuse accroupie is a fully enshrouded, crouching woman in three-quarter profile who bows her head and shuts her eyes, refusing to acknowledge the viewer. Enlarged to fill the entire canvas, this figure, although destitute, has a monumentality and presence that belies her low socioeconomic status.

Careful examination of the painting surface using direct and raking light revealed distinct surface textures and craquelure patterns that do not match the visible composition. More precisely, in the background area and right shoulder of the crouching woman, thinly painted

Electronic supplementary material The online version of this article (https://doi.org/10.1007/s42452-020-3130-4) contains supplementary material, which is available to authorized users.

Emeline Pouyet, emelinepouyet@gmail.com | ${ }^{1}$ Center for Scientific Studies in the Art, Northwestern University, 2145 Sheridan Rd, Evanston, IL 60208, USA. ${ }^{2}$ Art Gallery of Ontario, Toronto, CA, Canada. ${ }^{3}$ Department of Scientific Research, National Gallery of Art, Washington, USA. ${ }^{4}$ European Synchrotron Radiation Facility, 71 avenue des Martyrs, 38043 Grenoble Cedex 9, France. 

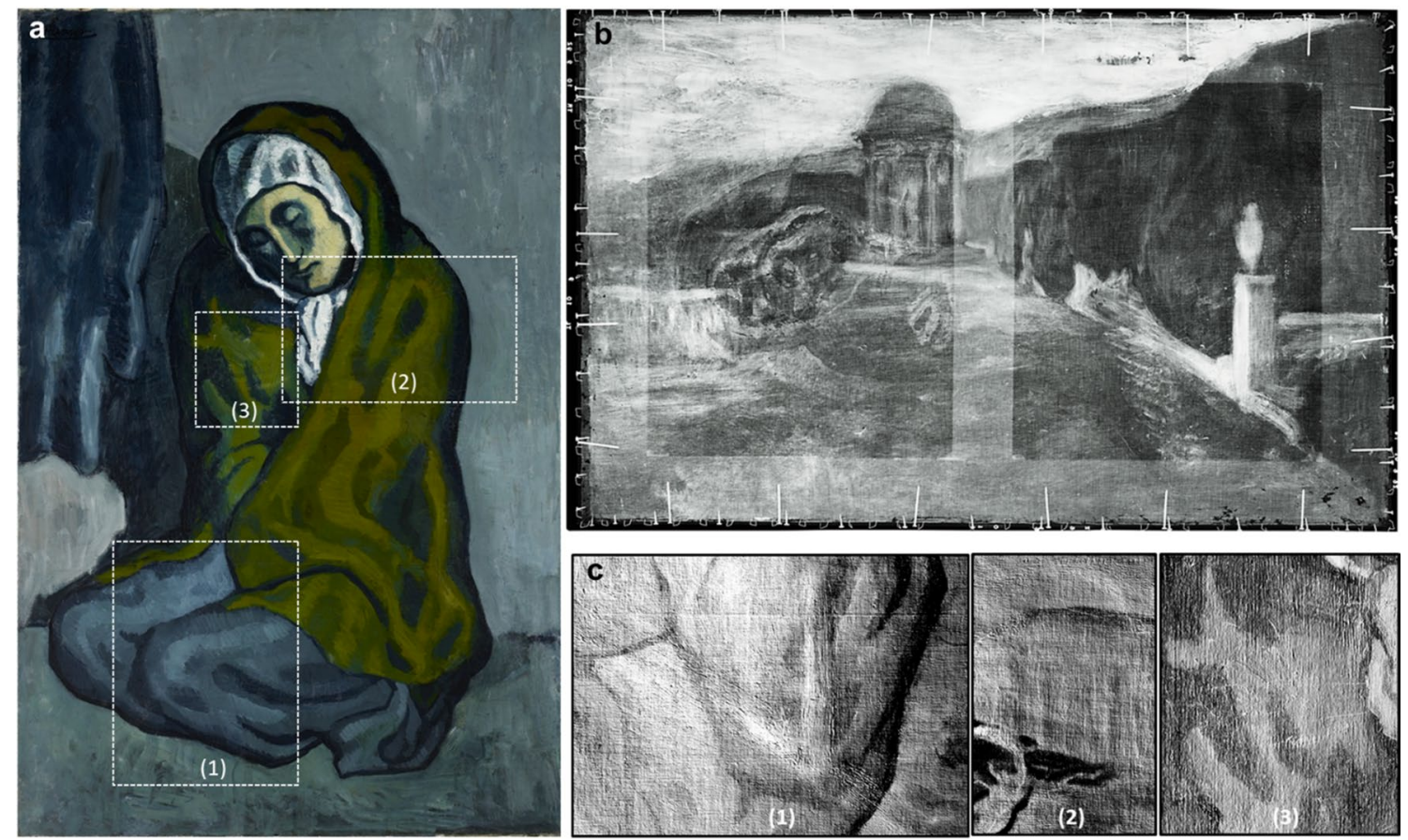

Fig. 1 a Visible image of La Miséreuse accroupie, 1902, Pablo Picasso, Oil on canvas $(101.3 \times 66 \mathrm{~cm})$, Art Gallery of Ontario, Toronto $\odot$ of the reproductions of works by Pablo Picasso: Pablo Picasso's Estate. VEGAP. Madrid, 2020. Permission to reproduce courtesy of VEGAP; b X-radiography of the painting rotated $90^{\circ}$

brushstrokes, paint losses and raised cracks exposed underlying colored and white paint layers. Picasso often made changes to his paintings, sometimes reusing canvases onto which images were already painted. For the most part, when he reworked a painting, he did so directly over earlier images, choosing not to scrape away the previous composition. Early in his career, financial constraints were certainly part of his motivation for reusing supports. However, for Picasso, the initial forms painted on a canvas also served as sources of inspiration [1]. To quote the artist: "A picture is not thought out and settled beforehand. While it is being done, it changes as one's thoughts change" [2].

Imaging using $\mathrm{x}$-radiography and infrared reflectography revealed numerous examples of reused canvases in Picasso's early works, offering conservators and art historians insights into the artist's process [1,3-8]. Within the last decade, the development of new portable in situ instruments [9-14] and access to state-of-the-art facilities [15] have increased possibilities to image and study both the surface and hidden compositions, providing further insight into Picasso's method and materials. Inspired by these recent studies, X-ray fluorescence and fiber optics reflectance spectroscopies were selected as key noninvasive analytical techniques due to their respective counter-clockwise, ( ) Art Gallery of Ontario c X-gradient of the surface normal vector calculated for the three areas denoted in a (area 1 and 2 have been rotated $90^{\circ}$ left in figure $\mathbf{c}$ as the elements imaged are part of the early landscape)

abilities to yield chemical information at the elemental and molecular level. ${ }^{1}$ This enabled analyses and imaging to be performed directly at the Art Gallery of Ontario. In addition, a few cross-sections were sampled and analyzed using Scanning Electron Microscopy, Fourier Transform spectroscopies and synchrotron micro X-ray Powder diffraction to better understand the paint composition and layering structure. Details about the methodology are provided in Supplementary Material.

\section{Results}

\subsection{X-radiography and photometric stereo imaging}

The existence of an underlying painting was determined in an x-radiography taken in 1992 . The x-radiography revealed the existence of a landscape when the painting is rotated left 90 degrees. It depicts a central circular domed

\footnotetext{
${ }^{1}$ Hyperspectral infrared reflectance image cubes were collected by J. Delaney, NGA, with a modified whiskbroom line-scanning imaging spectrometer prior to this work; the results, however, are not presented in this paper.
}

\section{SN Applied Sciences}




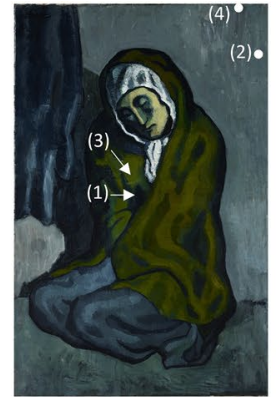

b

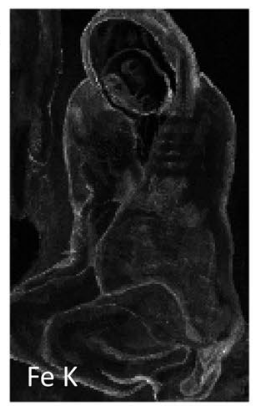

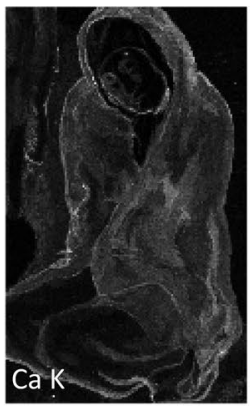
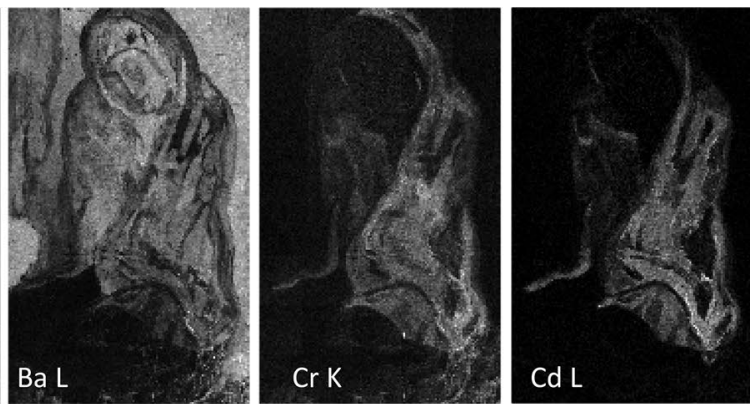

$\max$

c
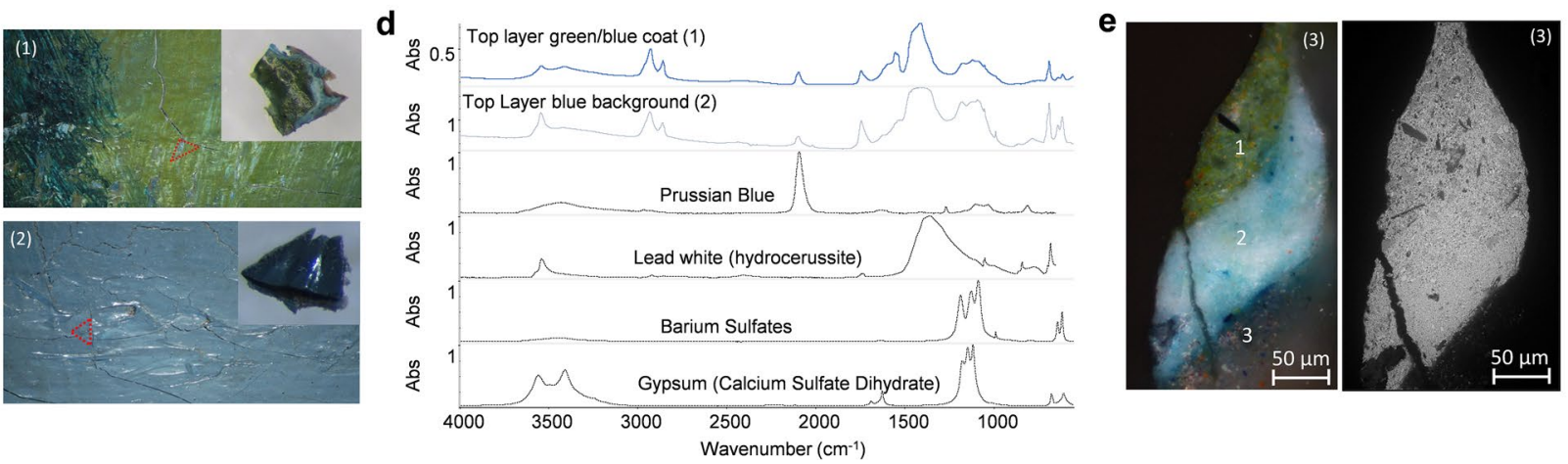

Fig. 2 a Visible picture (๔) of the reproductions of works by Pablo Picasso: Pablo Picasso's Estate. VEGAP. Madrid, 2020 Permission to reproduce courtesy of VEGAP) overlapped with sample locations; b elemental maps obtained by MA-XRF (step size: $4 \times 4 \mathrm{~mm}^{2}$, map size: $800 \times 480 \mathrm{~mm}^{2}$ ) characteristic of $\mathrm{Fe}, \mathrm{Ca}, \mathrm{Ba}, \mathrm{Cr}$ and $\mathrm{Cd}$ lines emission lines; c details visible picture of the sampling area for samples (1) and (2); d $\mu$ FTIR results of top blue and green layers of samples (1) and (2) compared to reference spectra from Aldrich FTIR library; e visible and BSE image of the mounted cross-section number (3), presenting 3 distinct layers temple structure with columns beside an open foreground with high hills and sky in the background (Fig. 1a, b). The stone post and finial in the lower right suggest a wall around the central space, which connects to another section on the middle left side. Scholars agree that this is likely a depiction of the Laberint d'Horta by an artist active in Barcelona at the turn of the century.

Using photometric stereo measurement, the main elements of this early composition were confirmed while providing additional clues about an underlying composition. The 3-D shape of the domed structure and column clearly appears in Fig. 1c. Photometric stereo imaging allows better differentiation of the richly painted strokes of the underlying landscape, confirming that the final composition was painted after the early composition had dried. The thick brushstrokes observed at the interface between the temple, hills and sky areas help further understand the complex relationship between La Miséreuse accroupie and the earlier composition. The contouring line representing the top of the hills briefly coincides with the woman's proper left back edge, offering another example of Picasso responding to a previous painting and repurposing passages as he created the new picture.

In addition, other disruptions of the surface texture were confirmed. In the background area and proper right shoulder of the crouching woman, thinly painted brushstrokes that do not match the surface composition, and paint losses (Fig. 1C, area (3)) were respectively imaged. They confirm preliminary visual microscopic observations that point towards the presence of another underlying structure.

\subsection{MA-XRF, FORS and micro-samples}

Hyperspectral imaging datasets from MA-XRF and FORS were used to uncover the different stages the painting underwent and to guide sampling in the four areas shown in Fig. 2a.

The visible aspect of the painting correlates with the distribution of the elements presented in Fig. 2 b. Iron is observed in high content in the blue areas of the painting. A stronger absorption of the same areas in the $1500-1650 \mathrm{~nm}$ domain is observed when compared to 1300-1500 nm, suggesting that Prussian Blue is the primary blue pigment used in the surface composition [15, 16]. The presence of Prussian Blue (PB) was confirmed in the different samples analyzed by $\mu X R D$ [17] and $\mu F T I R$ analyses, using the characteristic single dominant IR band of the $C \equiv N$ stretch arising ca. $2095 \mathrm{~cm}^{-1}$ [18]. Examples of this strong absorption are shown in Fig. $2 d$ for the top 

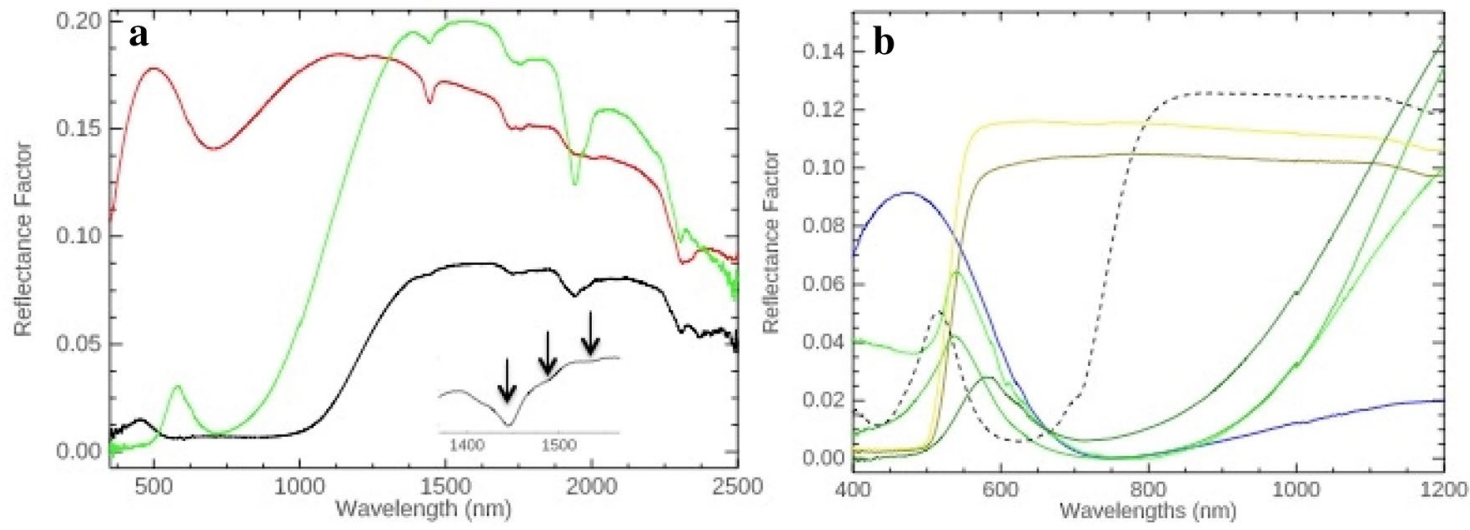

Fig. 3 Diffuse reflectance spectra from the painting and reference samples: a Prussian blue from dark outline of figure (black), lead white and Prussian blue of the head scarf (red), typical spectrum of green paint of shawl (green) having the $1942 \mathrm{~nm}$ band shoulder typical of gypsum. Inset the three absorption features of $-\mathrm{OH}$

layer of sample (1) and (2). PB is always found in combination with hydrocerussite $\left(2 \mathrm{PbCO}_{3} \cdot \mathrm{Pb}(\mathrm{OH})_{2}\right)$, exhibiting characteristic IR absorption bands at 3530, 1400, 1045, and $683 \mathrm{~cm}^{-1}$ [19] and characteristic XRD pattern [20]. The absence of cerussite was confirmed by $\mu$ XRD in sample (3) layer 1. FORS confirmed the presence of Prussian blue with some lead white (hydrocerussite owing to the $1446 \mathrm{~nm}$ feature of the $-\mathrm{OH}$ group) in the background behind the woman and in her white-blue headscarf (Fig. 3a). The dark outline of the woman and her clothes were painted with concentrated Prussian blue (Fig. 3a) and present higher content in Ca element (Fig. 2b), pointing toward the use of ivory black mixed with PB pigment. No samples from black outlines have been taken, however FORS analyses confirm the presence of a black infrared absorbing pigment. Ivory black has been identified using SEM-EDX in all samples as dispersed particles rich in $\mathrm{Ca}$ and $\mathrm{P}$, and its presence has been confirmed in the background area (sample 2) by $\mu$-FTIR analyses using the sharp characteristic absorbance band at $2013 \mathrm{~cm}^{-1}$.

Barium based pigment was also identified in high amounts in the visible composition, more particularly in the blue and white background area, in the woman's flesh tones and in her shawl. In the samples coming from the background area (2) and in the woman's shawl (1), barium sulfate $\left(\mathrm{BaSO}_{4}\right)$ was identified by the infrared bands at about $1185,1120,100$, and $983 \mathrm{~cm}^{-1}$ and the doublet at $630-610 \mathrm{~cm}^{-1}$ (Fig. 2d). However, the element barium has not been detected using the MA-XRF in the woman's garment, where lead and iron are the two main elements related solely to the surface composition (Fig. 2b).

The green area of her shawl contains at the micro- (sample (3) layer1) and macro- scale different ratios of $\mathrm{Cd}, \mathrm{Cr}$, $\mathrm{Fe}$, attributable to some lead white and gypsum; $\mathbf{b}$ examples of the variation spectra from the green shawl (light, medium and dark green) and a site of Prussian blue with lead white (blue), plus reference spectra of cadmium yellow (yellow) and chrome yellow (dark yellow) as well as viridian (dashed line)

$\mathrm{Pb}, \mathrm{Ca}$ and $\mathrm{Ba}$. FORS data combined with micro-analyses confirm that the shawl is painted with a mixture of Prussian blue with a yellow pigment (Fig. 3b) and lead white. All of the reflectance spectra from the shawl have a broad band from 800 to $1200 \mathrm{~nm}$, which is indicative of Prussian blue (Fig. 3b). Yellow pigments, with the exception of ochres, are difficult to identify by FORS. The $\mathrm{Cd}$ and $\mathrm{Cr}$ elemental maps, obtained by MA-XRF, overlap in the robe (Fig. 2b) with the exception of the top of the robe where $\mathrm{Cr}$ dominates. Comparing the reflectance spectra of cadmium yellow medium (reflectance transition at $527 \mathrm{~nm}$ ) and chrome yellow (reflectance transition at $535 \mathrm{~nm}$ ) suggests both pigments could explain the shifted peak to the green. A comparison of the reflectance spectrum of viridian looks less promising for this pigment to have been used in painting the shawl. Of note in many but not all of the green areas FORS spectral evidence for gypsum was observed from the vibrational features associated with its $-\mathrm{OH}$ groups (see inset in Fig. 3a), which might be from filler in the yellow paint.

A mixture of lead white, $\mathrm{PB}$, cadmium-sulfide (CdS), chrome yellow, barium white, gypsum and ivory black is proposed to create the different shades and tints of the shawl based on combined in situ and micro-analyses.

Using MA-XRF, a pentimento has been imaged and characterized as illustrated in Fig. 4. It allowed the determination of a link with other works the artist made during the same period, particularly a watercolor that was recently sold at auction (Fig. 4c). It also provided supplementary information about the palette composition of this underlying area.

The presence of a high amount of hydrocerussite (identified using $\mu \mathrm{XRD}$ and $\mu \mathrm{FTIR}$ in sample (3) layer 2 ) used to 

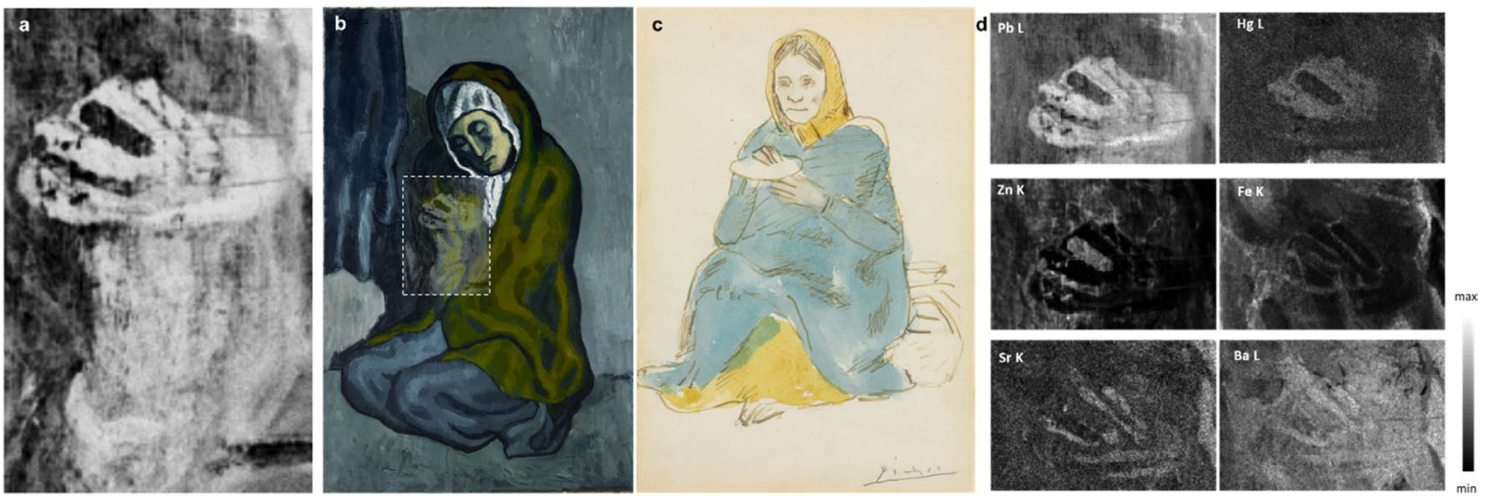

Fig. 4 a Detail Pb L map (step size $1 \times 1 \mathrm{~mm}^{2}$-area $120 \times 230 \mathrm{~mm}^{2}$ ) acquired in area highlighted in $\mathbf{b}$; $\mathbf{b}$ Visible picture (๑ of the reproductions of works by Pablo Picasso: Pablo Picasso's Estate. VEGAP. Madrid, 2020. Permission to reproduce courtesy of VEGAP) over- lapped with $\mathrm{Pb} \mathrm{L}$ map; c privately owned watercolor from Picasso dated from the same period; d MA-XRF Pb L, Hg L, Zn K, Fe K, Sr K and Ba L maps (step size $1 \times 1 \mathrm{~mm}^{2}$-area $150 \times 100 \mathrm{~mm}^{2}$ )
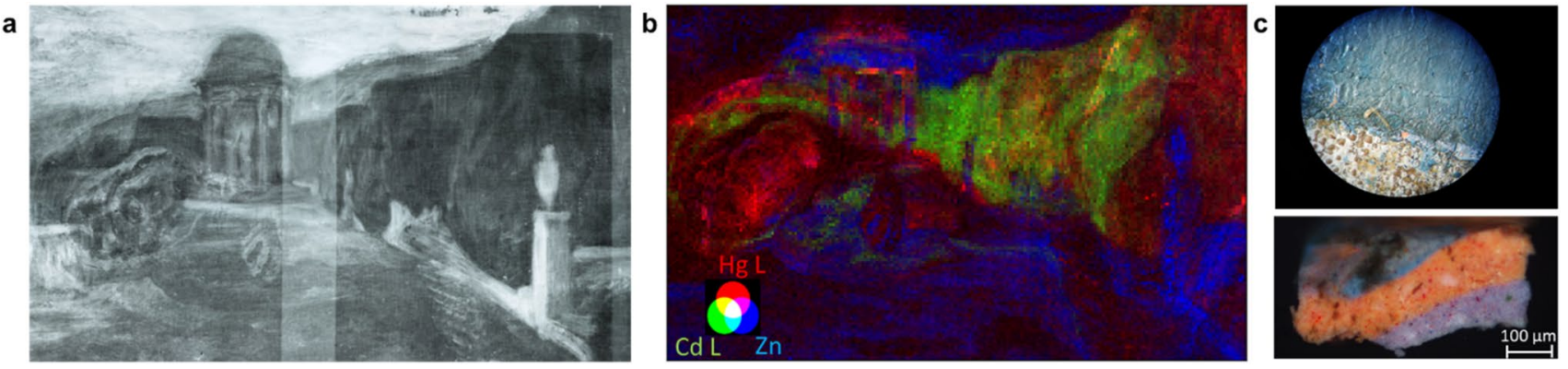

Fig. 5 a X-radiography of the area analyzed by MA-XRF; $\mathbf{b}$ composite image using MA-XRF Hg L-, Cd L- and Zn K- maps (respectively red, green and blue); $\mathbf{c}$ from top to bottom: detail picture of the sampling area 4, mounted cross section sample 4

paint this underlying area was key to allow the imaging of the former composition. MA-XRF Pb L emission map (Fig. 4a) confirms the presence of the woman's former right arm and her hand, which holds a circular shape with her thumb underneath and the fingers on top. The flesh tones represented in this pentimento use a mixture of lead white and $\mathrm{Hg}$-based pigments, similar to those observed in the surface composition. Sr and Ba- based paints were found together in the area of the edges of the fingers and the circular shape. Finally, Fe-based pigment, identified as PB by $\mu$ XRD and $\mu F T I R$, was used to outline the contour of the fingers.

Based on MA-XRF results rendering images presented in Fig. $4 a, b$ and $d$, further information can be deduced about Picasso's creative process on top of the preliminary information regarding his palette. By careful examination of the $\mathrm{Pb}-\mathrm{L}$ and $\mathrm{Hg}-\mathrm{L}$ maps, a low count area can be identified in the vicinity of the ring finger (the second finger from the left side of the Hg-L map in Fig. $4 \mathrm{~d}$ ). This decrease in the $\mathrm{Pb}$ and $\mathrm{Hg}$ is anti-correlated to the increase of $\mathrm{Zn}$, although the former is clearly identified in the underlying landscape only. Thus, it is here proposed that Picasso scraped away part of the flesh tone of the hand, slightly modifying the original orientation of the fingers, prior to painting over it with thinly applied paint to render the shawl that now completely covers the torso of the figure.

MA-XRF and micro-samples also revealed previously unknown details of the palette of the underlying landscape, illustrated in Fig. 5.

The open cracks affecting the blue background reveal pink tints from the original skyline. More particularly, mercury has been detected in high amount using MAXRF within this area. Sample 4 from the top left corner of the painting confirms the presence of a vermilion-rich layer with a few cadmium sulfide particles underneath the actual blue layer. Cadmium, mercury and barium are all elements detected in high amount in the hills area (MAXRF only, no sample was taken in this area). Zn with traces of cobalt is observed near the right corner of the column and wall as seen in the $1992 \mathrm{x}$-radiography. $\mathrm{Zn}$-rich particles have been identified as zinc white $(\mathrm{ZnO})$ by $\mu \mathrm{XRD}$ in sample (3) layer 3. 
Finally, the canvas has a uniform white ground consisting of hydrocerussite that was used to prime the linen canvas, which was identified through microscopic analyses and twisting test (Restoration and Conservation department Museu Picasso de Barcelona and ART-LAB).

\section{Conclusion}

A multi- technique approach, combined with art historical research has allowed reconstruction of the creative process used by Pablo Picasso to paint La Miséreuse accroupie, revealing new insights into the artist's pentimenti and a previous underlying landscape. Imaging and pigment mapping have revealed the presence of the figure's proper right hand holding a circular object that correlates to a known watercolor. Additionally, the palette used to paint La Miséreuse accroupie has been determined, adding to the current body of knowledge of Picasso's pigments of the Blue period [11, 15, 21]. In this work, PB is the main blue pigment identified, mixed with lead white, ivory black, barium sulfate, cadmium sulfide, gypsum and chrome yellow to create the different tints and contours of the composition. In the underlying composition, another palette based on the use zinc-based white pigment mixed with vermilion, iron earths, $\mathrm{Cd}$, and Ba-based pigments was determined, depicting a landscape with cool white architectural elements against a backdrop of warm orange-yellow hills. While the site of this landscape has been located, further research must be conducted if the artist is to be positively identified.

Acknowledgements The Advanced Light Source at the Lawrence Berkeley National Laboratory is supported by the Office of Science, Office of Basic Energy Sciences, Scientific User Facilities Division of the U.S. Department of Energy under Contract No. DE-AC0205CH11231. Sponsorship from the Museu Picasso, Barcelona, to cover permission fees for the reproduction of works by Picasso is gratefully acknowledged.

\section{Compliance with ethical standards}

Conflict of interest On behalf of all authors, the corresponding author states that there is no conflict of interest.

\section{References}

1. Hoenigswald A (1997) Works in PROGRESS: Pablo Picasso's hidden images. In: McCully M (ed) Picasso: the early years, 18921906. National gallery of art, Washington, pp 299-309

2. Ashton D (1972) Picasso on art: a selection of views, Da Capo

3. Belloli L (2005) Lost paintings beneath Picasso's La Coiffure. Metrop Mus J 40:151-162
4. Gedo MM (1986) A youthful genius confronts His Destiny: Picasso's" Old Guitarist" in The Art Institute of Chicago. Art Inst Chic Mus Stud 12:153-165

5. Gual M, Jiménez R (2013) Journey through the blue: La Vie: Museu Picasso, Barcelona, 10 October 2013-19 January 2014, Ajuntament de Barcelona, Institut de Cultura

6. Nicolson B (1969) X-rays at Agnew's. Burlingt Mag 111:165-171

7. Barcelona MPD (2019) Videos of the talks presented at the international symposium «Around Picasso: an insight into the relationship between material choices and failure mechanisms», 2018-Case study 6. Shank Will: The revelation of what lies beneath: the link between Picasso's Rue de Montmartre (1900) and Le Moulin de la Galette (1900)

8. Tinterow G, Stein SA (2010) Picasso in the Metropolitan Museum of Art, Metropolitan Museum of Art, pp 57-59

9. Alfeld M, de Viguerie L (2017) Recent developments in spectroscopic imaging techniques for historical paintings-a review. Spectrochim Acta Part B 136:81-105

10. Barten J, Delaney JK (2018) Pablo Picasso's woman ironing and the portrait hidden beneath. In: Fontanella MM (ed) Thannhauser Collection: French Modernism at the Guggenheim, pp 151-155

11. Defeyt $C$, Walter $P$, Rousselière $H$, Vandenabeele $P$, Vekemans $B$, Samain L, Strivay D (2018) New insights on Picasso's Blue Period Painting La famille Soler. Stud Conserv 63:24-35

12. Delaney JK, Thoury M, Zeibel JG, Ricciardi P, Morales KM, Dooley KA (2016) Visible and infrared imaging spectroscopy of paintings and improved reflectography. Heritage Sci 4:6

13. Ford T, Van der Snickt G, Janssens K (2018) Macro-XRF scanning a Picasso's Menage de pauvres: a case study. In: Publications A (ed) Picasso, Picabia, Ernst: new perspectives, pp 12-15

14. Sessa C, Jiménez de Garnica R, Rosi F, Fontana R, Garcia JF (2016) A Study of Picasso's painting materials and techniques in six of his early portraits. J Am Inst Conserv 55:198-216

15. Favero PA, Mass J, Delaney JK, Woll AR, Hull AM, Dooley KA, Finnefrock AC (2017) Reflectance imaging spectroscopy and synchrotron radiation X-ray fluorescence mapping used in a technical study of The Blue Room by Pablo Picasso. Heritage Sci 5:13

16. Delaney JK, Walmsley E, Berrie BH, Fletcher CF (2005) Multispectral imaging of paintings in the infrared to detect and map blue pigments. In: Proceedings of the national academy of sciences, p 120

17. Buser H, Schwarzenbach D, Petter W, Ludi A (1977) The crystal structure of Prussian blue: Fe4 [Fe (CN) 6] 3. xH2O. Inorg Chem $16: 2704-2710$

18. Berry BH (1997) Artists' pigments. A handbook of their history and characteristics, vol 3, pp 191-217

19. Rutherford JG, Künn H, Chase WT (1993) Artists' pigments. A handbook of their history and characteristics, vol 2, pp 67-79

20. Martinetto $P$, Anne M, Dooryhee $E$, Walter $P$, Tsoucaris G (2002) Synthetic hydrocerussite, $2 \mathrm{PbCO}_{3} \cdot \mathrm{Pb}(\mathrm{OH}) 2$, by X-ray powder diffraction. Acta Crystallogr C 58:i82-i84

21. Langley A, Muir K, Bezur A (2013) Looking below the surface of Picasso's the old guitarist. In: Wallert A (ed) Painting techniques, history, materials and studio practice, 5th international symposium, Amsterdam, pp 258-263

Publisher's Note Springer Nature remains neutral with regard to jurisdictional claims in published maps and institutional affiliations. 